\title{
Evaluation of cephalometric characteristics and skeletal maturation of the cervical vertebrae and hand-wrist in girls with central precocious puberty
}

\author{
Sung-Tae Kang ${ }^{\text {a }}$ (1) \\ Sung-Hwan $\mathrm{Choi}^{\mathrm{a}, \mathrm{b}}$ \\ Kyung-Ho Kim ${ }^{\mathrm{c}}$ \\ Chung-Ju Hwang ${ }^{a}$ (1)
}

${ }^{a}$ Department of Orthodontics, Institute of Craniofacial Deformity, Yonsei University College of Dentistry, Seoul, Korea

${ }^{\mathrm{b}}$ BK21 PLUS Project, Yonsei University College of Dentistry, Seoul, Korea

'Department of Orthodontics, Gangnam Severance Dental Hospital, Institute of Craniofacial Deformity, Yonsei University College of Dentistry, Seoul, Korea
Objective: This study aimed to evaluate the differences in cephalometric characteristics and skeletal maturation in girls with central precocious puberty (CPP) via lateral and hand-wrist radiographs. We also aimed to identify the indicators that are most effective for determining skeletal maturity in these patients. Methods: The study included 70 Korean girls (mean age, $8.5 \pm 0.5$ years) diagnosed with CPP at the Department of Pediatrics, and 48 normal healthy age-matched girls who visited the Department of Orthodontics and had no history of hormone treatment or growth problems. Skeletal maturation was evaluated using lateral cephalometric and hand-wrist radiographs using cervical vertebrae maturation indicators (CVMI) and skeletal maturity indicators (SMI). Results: The mean mandibular plane angle was smaller in the CPP group than in the control group $\left(35.8^{\circ} \pm 4.9^{\circ}\right.$ vs. $\left.39.0^{\circ} \pm 6.5^{\circ}\right)$, resulting in greater posterior facial height $(p=0.003)$. SMl was significantly greater in the CPP group $(3.5 \pm 1.4$ vs. $2.0 \pm 1.0)$ than in the control group $(p=0.001)$ and was significantly associated with CPP $(r=0.492 ; p=0.001)$, whereas CVMI was not. Conclusions: In comparison with the control group, the CPP group exhibited a smaller mandibular plane angle, greater posterior facial height, and greater skeletal maturation. SMI may be more suitable than CVMl for determining skeletal maturation in CPP. Hand-wrist radiography is recommended in addition to lateral cephalogram for predicting growth in girls with CPP.

[Korean J Orthod 2020;50(3):181-187]

Key words: Cephalometrics, Skeletal maturation, Central precocious puberty, Hand-wrist

Received October 23, 2019; Revised December 16, 2019; Accepted January 13, 2020.

Corresponding author: Chung-Ju Hwang.

Professor, Department of Orthodontics, Institute of Craniofacial Deformity, Yonsei University College of Dentistry, 50-1 Yonsei-ro, Seodaemun-gu, Seoul 03722, Korea. Tel +82-2-2228-3106 e-mail hwang@yuhs.ac

How to cite this article: Kang ST, Choi SH, Kim KH, Hwang CJ. Evaluation of cephalometric characteristics and skeletal maturation of the cervical vertebrae and handwrist in girls with central precocious puberty. Korean J Orthod 2020;50:181-187.

(C) 2020 The Korean Association of Orthodontists.

This is an Open Access article distributed under the terms of the Creative Commons Attribution Non-Commercial License (http://creativecommons.org/licenses/by-nc/4.0) which permits unrestricted non-commercial use, distribution, and reproduction in any medium, provided the original work is properly cited. 


\section{INTRODUCTION}

Accurate prediction of the facial growth pattern and evaluation of growth stage are essential to the success of orthopedic treatment in children. The peak of mandibular growth during puberty is a critical time to resolve skeletal discrepancies. ${ }^{1-3}$ Puberty begins after gonadotropin-releasing hormone ( $\mathrm{GnRH})$ is secreted, and the height of puberty is characterized by accelerated maxillary and mandibular growth. ${ }^{4}$

Due to recent improvements in living standards and nutrition around the world, the onset of puberty is accelerating, especially in girls. ${ }^{5}$ Skeletal maturation is accelerated in response to early exposure to sex hormones, resulting in differences between bone age and chronologic age. Precocious puberty is defined as the appearance of Tanner Stage 2 secondary sexual characteristics such as breast buds in girls and testicular volume $>3-4$ $\mathrm{mL}$ in boys before the normal age for puberty onset. Generally, the onset of sexual maturation before the age of 8 years in girls and 9 years in boys is considered abnormal. ${ }^{6,7}$ Precocious puberty is classified as either central (GnRH-dependent) or peripheral (GnRH-independent), and central precocious puberty (CPP) accounts for approximately $80 \%$ of the cases.

Lateral cephalometric and hand-wrist radiography can be used to assess skeletal maturation in CPP. In 1995, Hassel and Farman ${ }^{8}$ suggested specific cervical vertebrae maturation indicators (CVMI) that could be determined via lateral cephalometric radiography. To analyze handwrist bone maturation, skeletal maturity indicators (SMI) were proposed by Fishman ${ }^{9}$ in 1982. In previous studies, correlations between cervical vertebrae maturity and hand-wrist bone maturity were high, ${ }^{10-12}$ and it was suggested that evaluation of cervical vertebrae maturity alone could replace hand-wrist bone maturity evaluation.

This study aimed to evaluate differences in cephalometric characteristics and skeletal maturation according to the occurrence of CPP by using lateral and handwrist radiography; it also attempted to determine which of these two methods is more effective for determining skeletal maturity in girls with CPP. The null hypothesis was that there is no difference in cephalometric characteristics and cervical vertebrae or hand-wrist maturation regardless of CPP in girls.
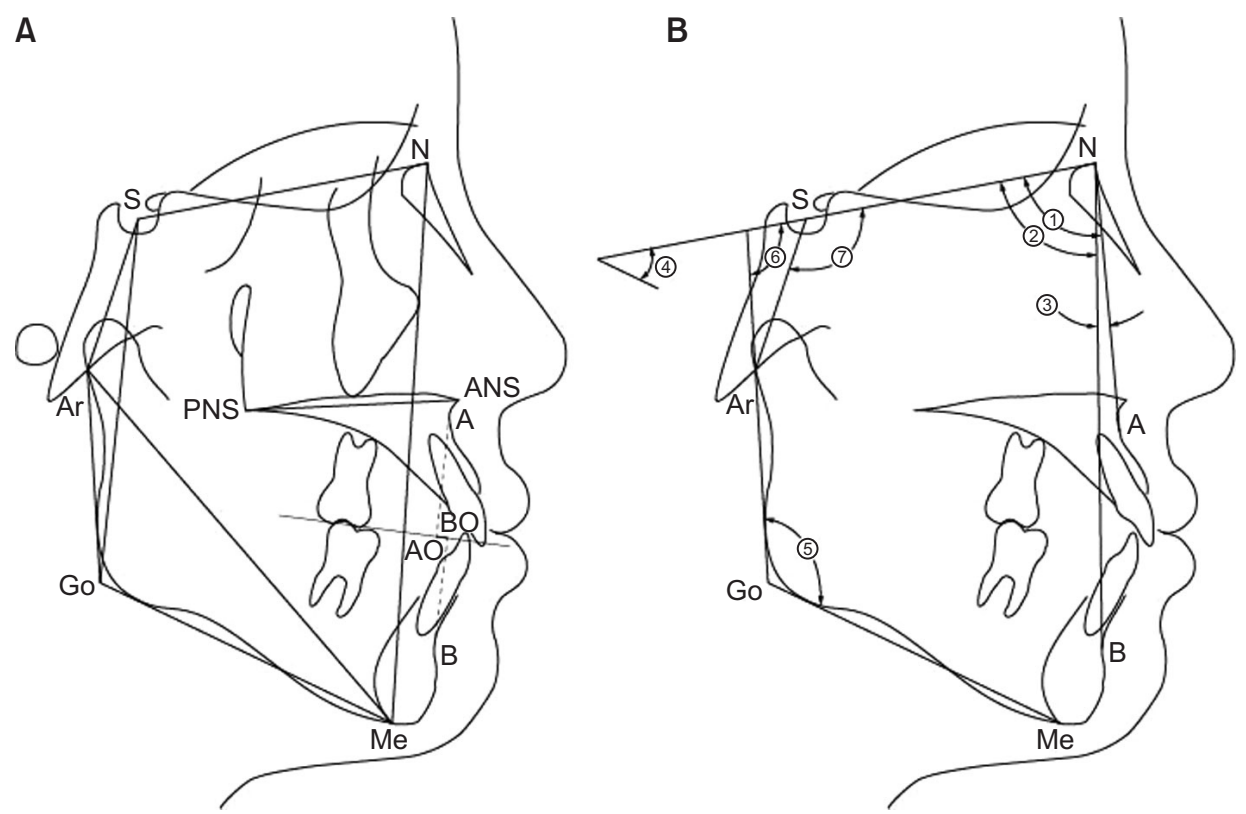

Figure 1. Cephalometric analysis. A, Linear measurements. N-S, Anterior cranial base length; S-Ar, posterior cranial base length; ANS-PNS, maxillary length; Ar-Go, mandibular ramus height; Go-Me, mandibular corpus length; Ar-Me, total mandibular length; N-Me, anterior facial height; S-Go, posterior facial height; A0-BO, wits appraisal. B, Angular measurements. (1) SNA, The relationship of the maxilla to the cranial base; (2) SNB, the relationship of the mandible to the cranial base; (3) ANB, the relationship between the maxilla and the mandible; (4) SN-GoMe, mandibular plane angle; (5) ArGo-Me, gonial angle; (6) SN-ArGo, ramal angle; 7 ) N-S-Ar, cranial base angle.

S, Sella turcica; N, nasion; Ar, articulare; ANS, anterior nasal spine; PNS, posterior nasal spine; $A$, point $A ; B$, point $B$; $A 0$, the point perpendicular to the occlusal plane at point $A ; B 0$, the point perpendicular to the occlusal plane at point $B$; Go, constructed gonion; Me, menton. 


\section{MATERIALS AND METHODS}

\section{Study sample and design}

The CPP group in the study included 70 Korean girls aged 7-9 years (mean age, $8.5 \pm 0.5$ years) who were diagnosed with CPP (peak luteinizing hormone level, $\geq 5$ IU/L; Tanner stage 2; breast budding before 8 years of age; bone age 1 year older than chronologic age) at the Department of Pediatrics. Bone age was measured by the Tanner-Whitehouse 3 (TW3) method, ${ }^{13}$ which was obtained by scoring and adding the grades for 13 bones (radius, ulna, short bones, and seven carpal bones), and converting it to bone age.

The control group included 48 normal healthy girls (mean age, $8.6 \pm 0.7$ years) who visited the Department of Orthodontics for orthodontic treatment and had no history of hormone treatment or growth problems. Based on data from previous studies, ${ }^{7,14}$ the numbers of girls in each group were determined via $\mathrm{G}^{*}$ Power ver. 3.1.9.2 (Dusseldorf University, Dusseldorf, Germany), with a $p$ value $<0.05$ indicating statistical significance. A power of $80 \%$ and an effect size of 0.8 was used for detecting the differences in skeletal maturation between the two groups. To enable assessment of skeletal maturation in the two groups, the minimum sample size in each group was 21. The study was approved by the Institutional Review Board of Yonsei University Hospital, Seoul, Korea (2-2019-0010).

\section{Radiographic analysis}

Lateral cephalograms were digitized using V-ceph

Table 1. Subjects' mean age (unit, yr)

\begin{tabular}{cccc}
\hline Characteristic & CPP $(\mathbf{n}=70)$ & Control $(\mathbf{n}=\mathbf{4 8})$ & $\boldsymbol{p}$-value \\
\hline Age (Lat) & $8.5 \pm 0.5$ & $8.5 \pm 0.6$ & 0.528 \\
Age (HW) & $8.1 \pm 1.1$ & $8.6 \pm 0.7$ & $0.012^{*}$ \\
\hline
\end{tabular}

Values are presented as mean \pm standard deviation.

CPP, Central precocious puberty; Age (Lat), chronological age when lateral cephalometric radiographs were obtained; Age (HW), chronological age when hand-wrist radiographs were obtained.

$p$-values were calculated by the Mann-Whitney $U$ test.

${ }^{*} p<0.05$. software (version 5.5; Osstem, Seoul, Korea), after which cephalometric characteristics were evaluated using ten linear and seven angular measurements selected with reference to a previous study (Figure 1). ${ }^{7}$ CVMI was analyzed using a method reported by Hassel and Farman, ${ }^{8}$ which is based on the shapes of the cervical vertebrae. To assess hand-wrist maturation, the SMl method suggested by Fishman ${ }^{9}$ (graded from 1 to 11) was used.

\section{Reproducibility}

Reproducibility was determined by comparing initial measurements with measurements obtained at repeated examinations. Twenty subjects were randomly selected from each group and the same observer repeated all measurements after 4 weeks. The method error for all cephalometric measurements was calculated using Dahlberg formula. Consequently, the errors ranged from 0.14 $\mathrm{mm}$ to $0.30 \mathrm{~mm}$ and from $0.20^{\circ}$ to $0.41^{\circ}$ for linear and angular measurements, respectively. The intraclass correlation coefficient was also used to calculate the method error, which was within 0.897-0.983 for all cephalometric measurements; the skeletal maturation indicators (CVMI and SMI) also exhibited high reliability.

\section{Statistical analysis}

All statistical analyses were conducted using IBM SPSS Statistics for Windows, version 20.0 (IBM Co., Armonk, NY, USA). To verify the normality of all data, the Shapiro-Wilk test was used. Differences in cephalometric measurements between the two groups were analyzed via the independent $t$-test. As a total of 17 cephalometric variables were considered in an equal number of $t$-tests, a $p$-value of $0.05 / 17$ was applied to avoid the chance of type 1 errors. The Mann-Whitney $U$ test was used to compare CVMl and SMl differences in the two groups. Correlations between the groups' CVMI and SMI were evaluated using the Spearman's rank correlation coefficient $(r<0.3$, very weak correlation; $0.3 \leq r<0.5$, weak correlation; $0.5 \leq r<0.7$, moderate correlation; 0.7 $\leq r<0.9$, strong correlation; $r \geq 0.9$, very strong correlation). ${ }^{15} \mathrm{~A} p$-value $<0.05$ was considered statistically significant.

Table 2. Distribution of TW3 bone age among participants in the two groups

\begin{tabular}{lccccccccc}
\hline \multirow{2}{*}{ Group } & \multicolumn{10}{c}{ TW3 bone age (yr) } \\
\cline { 2 - 9 } & $\mathbf{6}$ & $\mathbf{6 . 0 1 - 7 . 0 0}$ & $\mathbf{7 . 0 1 - 8 . 0 0}$ & $\mathbf{8 . 0 1 - 9 . 0 0}$ & $\mathbf{9 . 0 1 - 1 0 . 0 0}$ & $\mathbf{1 0 . 0 1 - 1 1 . 0 0}$ & $\mathbf{1 1 . 0 1 - 1 2 . 0 0}$ & $\mathbf{1 2 . 0 1 - 1 3 . 0 0}$ & $\mathbf{1 3}<$ \\
\hline CPP & $3(4.3)$ & $2(2.9)$ & $4(5.7)$ & $12(17.1)$ & $26(37.1)$ & $11(15.7)$ & $6(8.6)$ & $4(5.7)$ & $2(2.9)$ \\
Control & $3(6.2)$ & $5(10.4)$ & $11(22.9)$ & $13(27.1)$ & $11(22.9)$ & $3(6.2)$ & $2(4.2)$ & $0(0.0)$ & $0(0.0)$ \\
\hline
\end{tabular}

Values are presented as number (\%).

TW3, Tanner-Whitehouse 3; CPP, central precocious puberty. 


\section{RESULTS}

This study included 70 girls with CPP (mean age, 8.5 \pm 0.5 years) and 48 normal healthy girls (mean age, $8.5 \pm 0.6$ years) as the control group (Table 1). Mean TW3 bone age was more than 1 year higher in the CPP group $(9.4 \pm 1.7$ years $)$ than the control group $(8.3 \pm$ 0.7 years). Additionally, in the CPP group, 49 girls (70\%) had bone age over 9 years, of which 6 (8.6\%) had bone age over 12 years (Table 2). In the control group, none of the girls were older than 12 years.

Table 3 shows that the mandibular ramus height of the CPP group $(43.3 \pm 3.8 \mathrm{~mm})$ was about $2 \mathrm{~mm}$ longer than that of the control group $(41.0 \pm 3.6 \mathrm{~mm})(p=$ 0.002). Likewise, the posterior facial height in the CPP group $(73.5 \pm 4.3 \mathrm{~mm})$ was about $3 \mathrm{~mm}$ longer than that in the control group $(70.3 \pm 4.3 \mathrm{~mm})(p=0.001)$. Additionally, the mandibular plane angle in the CPP

Table 3. Comparison of cephalometric measurements between the two groups

\begin{tabular}{|c|c|c|c|}
\hline Variable & $\operatorname{CPP}(n=70)$ & Control $(n=48)$ & $p$-value \\
\hline \multicolumn{4}{|l|}{ Linear measurements (mm) } \\
\hline Anterior cranial base length (N-S) & $66.4 \pm 3.0$ & $66.2 \pm 3.6$ & 0.850 \\
\hline Posterior cranial base length (S-Ba) & $33.0 \pm 3.0$ & $32.0 \pm 2.8$ & 0.094 \\
\hline Maxillary length (ANS-PNS) & $48.8 \pm 2.8$ & $47.7 \pm 2.5$ & $0.036^{*}$ \\
\hline Mandibular ramus height (Ar-Go) & $43.3 \pm 3.8$ & $41.0 \pm 3.6$ & $0.002^{* *}$ \\
\hline Mandibular corpus length (Go-Me) & $70.2 \pm 4.0$ & $68.4 \pm 4.3$ & $0.021^{*}$ \\
\hline Total mandibular length (Ar-Me) & $99.6 \pm 4.8$ & $97.5 \pm 4.5$ & $0.022^{*}$ \\
\hline Anterior facial height (N-Me) & $115.4 \pm 4.8$ & $115.3 \pm 6.9$ & 0.971 \\
\hline Posterior facial height (S-Go) & $73.5 \pm 4.3$ & $70.3 \pm 4.3$ & $0.001^{* *}$ \\
\hline Facial height ratio (\%) & $63.7 \pm 3.8$ & $61.1 \pm 4.7$ & $0.001^{* *}$ \\
\hline Wits appraisal (Wits) & $-1.5 \pm 3.6$ & $-2.2 \pm 3.3$ & 0.284 \\
\hline \multicolumn{4}{|l|}{ Angular measurements $\left({ }^{\circ}\right)$} \\
\hline Cranial base angle (N-S-Ar) & $125.9 \pm 5.2$ & $125.1 \pm 5.9$ & 0.468 \\
\hline Ramal angle (SN-ArGo) & $94.6 \pm 4.0$ & $90.6 \pm 10.1$ & $0.012^{*}$ \\
\hline Gonial angle (Ar-Go-Me) & $121.1 \pm 5.7$ & $124.6 \pm 7.1$ & $0.004^{* *}$ \\
\hline Mandibular plane angle (SN-GoMe) & $35.8 \pm 4.9$ & $39.0 \pm 6.5$ & $0.003^{* *}$ \\
\hline Maxilla-cranial base relation (SNA) & $79.9 \pm 3.5$ & $78.1 \pm 3.7$ & $0.008^{* *}$ \\
\hline Mandible-cranial base relation (SNB) & $76.3 \pm 3.0$ & $75.1 \pm 4.0$ & 0.066 \\
\hline Maxilla-mandible relation (ANB) & $3.6 \pm 2.4$ & $3.0 \pm 2.2$ & 0.150 \\
\hline
\end{tabular}

Values are presented as mean \pm standard deviation.

CPP, Central precocious puberty.

$p$-values were calculated by the independent $t$-test.

As a total of 17 cephalometric variables were considered in an equal number of $t$-tests, a $p$-value of $0.05 / 17$ was applied to avoid the chance of error type I errors.

${ }^{*} p<0.05,{ }^{* *} p<0.01$.

Table 4. Comparison of differences in the mean values, medians, ranges, and standard deviations of CVMI and SMI between the two groups

\begin{tabular}{|c|c|c|c|c|c|c|c|c|c|}
\hline \multirow[b]{2}{*}{ Variable } & \multicolumn{4}{|c|}{$\operatorname{CPP}(n=70)$} & \multicolumn{4}{|c|}{ Control $(n=48)$} & \multirow[b]{2}{*}{$p$-value } \\
\hline & Mean & Median & Range & $\begin{array}{l}\text { Standard } \\
\text { deviation }\end{array}$ & Mean & Median & Range & $\begin{array}{l}\text { Standard } \\
\text { deviation }\end{array}$ & \\
\hline CVMI & 1.4 & 1 & $1-3$ & 0.6 & 1.2 & 1 & $1-3$ & 0.4 & 0.232 \\
\hline SMI & 3.5 & 3 & $1-7$ & 1.4 & 2.0 & 2 & $1-4$ & 1.0 & $0.001^{* *}$ \\
\hline
\end{tabular}

CVMI, Cervical vertebral maturation indicator; SMI, skeletal maturity indicator; CPP, central precocious puberty. $p$-values of SMI and CVMI were calculated with the Mann-Whitney $U$ test.

** $p<0.01$. 
Table 5. Distribution of CVMI and SMI among the participants in the two groups

\begin{tabular}{|c|c|c|c|c|c|c|c|c|c|c|}
\hline \multirow{2}{*}{ Group } & \multicolumn{3}{|c|}{ CVMI } & \multicolumn{7}{|c|}{ SMI } \\
\hline & 1 & 2 & 3 & 1 & 2 & 3 & 4 & 5 & 6 & 7 \\
\hline СРP & 46 (65.7) & $20(28.6)$ & $4(5.7)$ & $4(5.7)$ & $6(8.6)$ & 34 (48.6) & $14(20.0)$ & $2(2.9)$ & $7(10.0)$ & $3(4.3)$ \\
\hline Control & $38(79.2)$ & $9(18.8)$ & $1(2.1)$ & $21(43.8)$ & $7(14.6)$ & $15(31.2)$ & $5(10.4)$ & $0(0.0)$ & $0(0.0)$ & $0(0.0)$ \\
\hline$p$-value & & 0.256 & & & & & $0.001^{* *}$ & & & \\
\hline
\end{tabular}

Values are presented as number (\%).

CVMI, Cervical vertebral maturation indicator; SMI, skeletal maturity indicators; $\mathrm{CPP}$, central precocious puberty. $p$-values were calculated by the chi-squared test.

${ }^{* *} p<0.01$.

group $\left(35.8 \pm 4.9^{\circ}\right)$ was about $3^{\circ}$ smaller than that in the control group $\left(39.0 \pm 6.5^{\circ}\right)(p=0.003)$.

In comparisons of skeletal maturation indicators, CVMl in the CPP group $(1.4 \pm 0.6)$ did not differ significantly from that in the control group (1.2 \pm 0.4$)$. However, SMl differed significantly in the two groups $(3.5 \pm 1.4$ in the CPP girls, $2.0 \pm 1.0$ in the control group $[p=0.001]$ ) (Table 4). The distributions of CVMI and SMl also shifted to higher values in the CPP group compared to those in the control group, indicating faster bone maturity (Table 5).

Correlations between the occurrence of CPP and each skeletal maturity indicator were analyzed (Table 6). CPP showed weakly significant correlation with SMl $(r=$ $0.492 ; p=0.001)$, and no significant correlation with CVMI $(r=0.150 ; p=0.105)$.

\section{DISCUSSION}

The incidence of CPP is increasing rapidly in Korea. Based on statistics accrued by the Health Insurance Review and Assessment Service in Korea from 2010 to 2018, the number of precocious puberty patients (disease code E301) increased by approximately 4 times, from 28.2 thousand to 102.8 thousand, while the total cost of medical treatment also rose from KRW 1.79 billion to KRW 5.22 billion. ${ }^{16}$ Additionally, the proportion of girls with precocious puberty was 10 times higher than that of boys.

Treating CPP in a timely manner is important for proper growth of a child's height and for prevention of psychological problems. In a previous study, dental maturation was investigated as a predictive indicator of CPP. ${ }^{17}$ However, in another study, girls with CPP showed faster dental maturation, an overgrown maxilla, a horizontal mandibular growth pattern, and vertical excess in the face. ${ }^{7}$ In this study, although the differences between the two groups were subtle and clinically insignificant, we demonstrated that girls with CPP exhibited greater posterior facial height and smaller mandibular plane angle than the control group, in linear and angular measurements derived from lateral cephalograms.
Table 6. Spearman correlation coefficients for CVMI and SMI between the two groups

\begin{tabular}{lcc}
\hline \multirow{2}{*}{ Variable } & \multicolumn{2}{c}{ Group } \\
\cline { 2 - 3 } & \multicolumn{1}{c}{$\boldsymbol{r}$} & $\boldsymbol{p}$-value \\
\hline CVMI & 0.150 & 0.105 \\
SMI & 0.492 & $0.001^{* *}$ \\
\hline
\end{tabular}

CVMI, Cervical vertebral maturation indicator; SMI, skeletal maturity indicators.

Spearman's rank correlation coefficient $(r)$.

${ }^{* *} p<0.01$.

In this study, the timing of lateral cephalogram and hand-wrist radiography were similar in the two groups, as were their ages; however, TW3 indicated that the CPP group exhibited a mean bone age that was 1.1 years greater than that of the control group. The distributions of CVMI and SMl suggested increased skeletal maturity in the CPP group. In some participants in the CPP group, SMI was particularly higher than CVMI (Figure 2).

Many previous studies suggest that CVMI is useful, and that lateral cephalogram can replace hand-wrist radiography without the patient being exposed to any additional radiation. ${ }^{18}$ However, in this current study, we demonstrated that compared to SMI, CVMI did not show a statistically significant difference in the CPP group. Only SMI showed a significantly weak correlation with CPP. Additionally, higher SMl was not observed in all the girls in the CPP group; however, the tendency for higher SMl was greater compared to the tendency for higher CVMl. Additionally, Lee et al. ${ }^{19}$ reported that compared to CVMI, the SMI was higher in a high mandibular plane angle group than a low mandibular plane angle group. This suggests the need for hand-wrist measurements in girls to precisely evaluate growth and development according to the vertical growth pattern.

The hand-wrist consists of many bones that ossify at different timings and at different rates. As the maturation occurs in a predictable order, and there are many ossification centers in relatively small sites, hand-wrist 

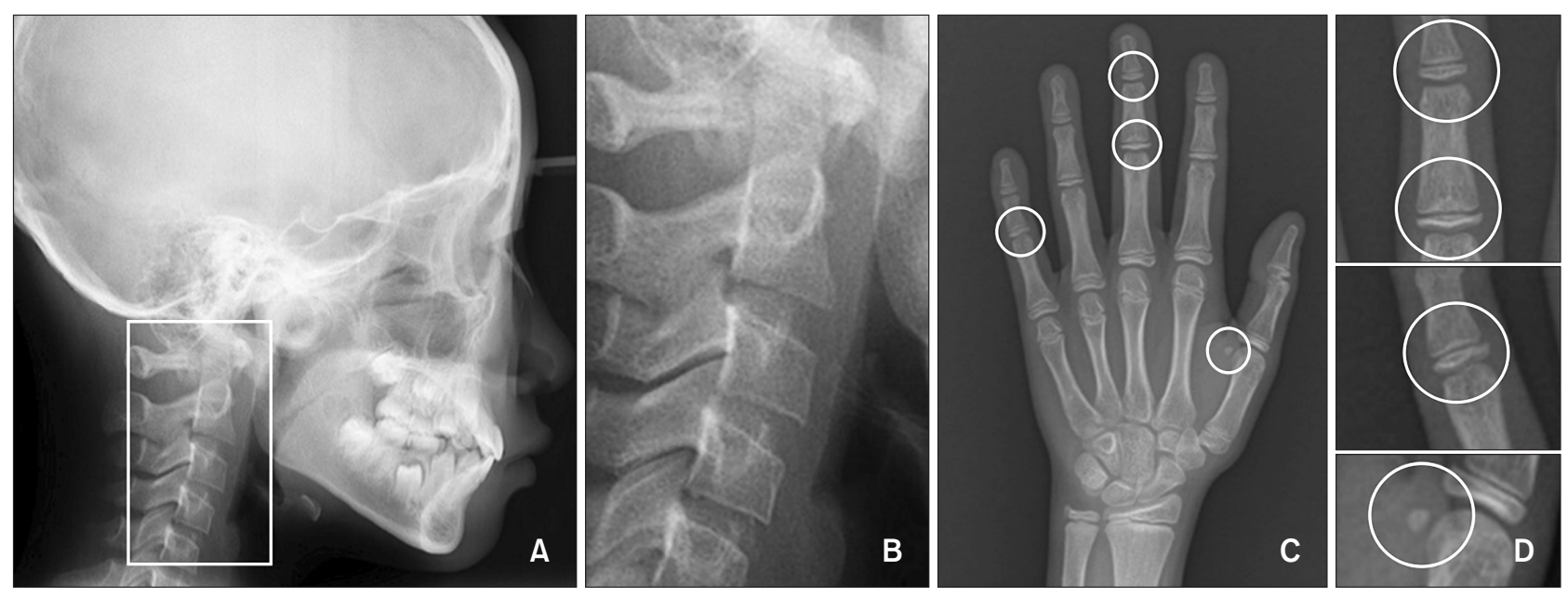

Figure 2. A central precocious puberty (CPP) patient exhibiting differing skeletal maturation stages on cervical vertebrae maturation indicators (CVMI) and skeletal maturity indicators (SMI). The lateral cephalogram represents CVMI 1 (A, B), and the hand-wrist radiograph represents stage SMI 6 (C, D). The CPP patient's lateral cephalogram and hand-wrist radiograph were taken at the age of 9.4 years. They were assessed as CVMI 1, SMI 6, and a Tanner-Whitehouse 3 bone age of 11.8 years.

radiographs are clinically important for the evaluation of bone maturity; the ossification of these bones provides a useful measure for identifying growth stages. TW3 and SMl are most commonly used in skeletal maturation assessment. TW3 allows for more accurate assessment of skeletal maturity, but SMl is relatively easy for clinical use because it takes less time and effort. Recent research comparing SMI and CVMI have reported that SMI is more accurate; however, this is still controversial. According to Warmeling et al., ${ }^{20} \mathrm{SMl}$ is the safest and most reliable due to morphologic alterations of the vertebrae CVMI; therefore, only CVMI is recommended when carpal radiography is not available. Compared with CVMI, SMI not only represents bone maturation staging but also ossification events. ${ }^{21}$ Hence, SMl can be useful in studies of the relationship between the timing of spheno-occipital synchondrosis fusion and skeletal maturation. ${ }^{22}$

The current study had several limitations. First, although the numbers of patients in each group were sufficient to enable informative comparisons of cephalometric measurements and skeletal maturity, the limited number of patients made it difficult to generalize the results of the study. Another potential study limitation is that CPP may not be the only factor that contributes to the acceleration of skeletal maturation, and other genetic and nutritional factors should be considered. Additionally, we did not evaluate the severity or diversity of CPP in this study. Therefore, based on these results, we cannot simply determine that skeletal maturation increases with decreasing mandibular plane angle or increasing posterior facial height in girls with CPP. Lastly, growth hormones as well as sex hormones play important roles in skeletal growth; hence, further studies are needed to elucidate the correlation between these hormones and craniofacial complex growth.

Based on the results of this study, it is recommended that hand-wrist radiography be performed in addition to lateral cephalogram. Furthermore, periodic skeletal maturity evaluation is required in the treatment of younger patients who exhibit abnormally advanced bone age. If a patient is suspected of having CPP, it is important that clinicians detect acceleration of skeletal maturation early, and consult with pediatricians to determine the optimal timing of hormonal treatment.

\section{CONCLUSION}

1. The null hypothesis of this study is rejected. Although it may not be clinically significant, girls with CPP exhibited earlier skeletal maturation, and there were significant increases in posterior facial height, and a decrease in mandibular plane angle.

2. SMI showed weakly significant correlation with CPP, whereas CVMI did not.

3. It is recommended that hand-wrist radiography and lateral cephalogram analysis should be performed for the prediction of growth in girls with CPP.

\section{CONFLICTS OF INTEREST}

No potential conflict of interest relevant to this article was reported. 


\section{REFERENCES}

1. Bishara SE. Facial and dental changes in adolescents and their clinical implications. Angle Orthod 2000;70:471-83.

2. Petrovic A, Stutzmann J, Lavergne J. Mechanisms of craniofacial growth and modus operandi of functional appliances: a cell-level and cybernetic approach to orthodontic decision making. In: Carlson DS, ed. Craniofacial growth theory and orthodontic treatment. Craniofacial growth series. Ann Arbor: University of Michigan, Center for Human Growth and Development; 1990. p.13-73.

3. Malmgren 0 , Omblus J, Hägg U, Pancherz H. Treatment with an orthopedic appliance system in relation to treatment intensity and growth periods. A study of initial effects. Am J Orthod Dentofacial Orthop 1987;91:143-51.

4. Björk A, Helm S. Prediction of the age of maximum puberal growth in body height. Angle Orthod 1967;37:134-43.

5. Parent AS, Teilmann G, Juul A, Skakkebaek NE, Toppari J, Bourguignon JP. The timing of normal puberty and the age limits of sexual precocity: variations around the world, secular trends, and changes after migration. Endocr Rev 2003;24:668-93.

6. Mul D, Hughes IA. The use of GnRH agonists in precocious puberty. Eur J Endocrinol 2008;159 Suppl $1: \mathrm{S} 3-8$.

7. Lee HK, Choi SH, Fan D, Jang KM, Kim MS, Hwang CJ. Evaluation of characteristics of the craniofacial complex and dental maturity in girls with central precocious puberty. Angle Orthod 2018;88:582-9.

8. Hassel B, Farman AG. Skeletal maturation evaluation using cervical vertebrae. Am J Orthod Dentofacial Orthop 1995;107:58-66.

9. Fishman LS. Radiographic evaluation of skeletal maturation. A clinically oriented method based on hand-wrist films. Angle Orthod 1982;52:88-112.

10. Al Khal HA, Wong RW, Rabie AB. Elimination of hand-wrist radiographs for maturity assessment in children needing orthodontic therapy. Skeletal Radiol 2008;37:195-200.

11. Szemraj A, Wojtaszek-Słomińska A, Racka-Pilszak $B$. Is the cervical vertebral maturation (CVM) method effective enough to replace the hand-wrist maturation (HWM) method in determining skeletal maturation?-A systematic review. Eur J Radiol 2018;102:125-8.

12. Terçarolli SP. Skeletal and vertebral age - a literature review. Ortop Rev Int Func 2005;1:400-11.

13. Tanner JM, White-house RH, Wenger DR. Atlas of children's growth, normal variation and growth disorders. J Pediatr Orthop 1983;3:531.

14. Choi SH, Fan D, Hwang MS, Lee HK, Hwang CJ. Effect of growth hormone treatment on craniofacial growth in children: idiopathic short stature versus growth hormone deficiency. J Formos Med Assoc 2017;116:313-21.

15. Hinkle DE, Wiersma W, Jurs SG. Applied statistics for the behavioral sciences. Boston: Houghton Mifflin College Division; 2003.

16. Health Insurance Review \&t Assessment Service (KR). Four-character subcategories statistics. Health Insurance Review \&t Assessment Service; 2019.

17. Baik JS, Choi JW, Kim SJ, Kim JH, Kim S, Kim JH. Predictive value of dental maturity for a positive gonadotropin-releasing hormone stimulation test result in girls with precocious puberty. J Korean Med Sci 2017;32:296-302.

18. Hoseini M, Zamaheni S, Bashizadeh Fakhar H, Akbari F, Chalipa J, Rahmati A. Comparative evaluation of the efficacy of hand-wrist and cervical vertebrae radiography for the determination of skeletal age. Iran J Radiol 2016;13:e21695.

19. Lee YS, Choi SH, Kim KH, Hwang CJ. Evaluation of skeletal maturity in the cervical vertebrae and handwrist in relation to vertical facial types. Korean $\mathrm{J}$ Orthod 2019;49:319-25.

20. Warmeling D, Rodrigues KM, Zastrow MD, Thiesen G. Comparative study of two skeletal maturation evaluation indexes. Rev Odonto Ciênc 2010;25:188-93.

21. Flores-Mir C, Nebbe B, Major PW. Use of skeletal maturation based on hand-wrist radiographic analysis as a predictor of facial growth: a systematic review. Angle Orthod 2004;74:118-24.

22. Jabour ASA. Assessment of spheno-occipital synchondrosis fusion timing and an evaluation of its relationship with skeletal maturity, dental maturity and mandibular growth [PhD dissertation]. Cleveland: Case Western Reserve University; 2017. 